\title{
Kernos
}

Revue internationale et pluridisciplinaire de religion grecque antique

10 | 1997

Varia

\section{St. GEORGOUDI, J.-P. VERNANT, Mythes grecs au figuré}

\section{Vinciane Pirenne-Delforge}

\section{(2) OpenEdition}

\section{Journals}

Édition électronique

URL : http://journals.openedition.org/kernos/677

DOI : $10.4000 /$ kernos. 677

ISSN : 2034-7871

Éditeur

Centre international d'étude de la religion grecque antique

Édition imprimée

Date de publication : 1 janvier 1997

Pagination : 338-339

ISSN : 0776-3824

Référence électronique

Vinciane Pirenne-Delforge, «St. Georgoud, J.-P. vernant, Mythes grecs au figuré », Kernos [En ligne], 10 |

1997, mis en ligne le 12 avril 2011, consulté le 24 septembre 2020. URL : http://

journals.openedition.org/kernos/677 ; DOI : https://doi.org/10.4000/kernos.677 
Gortyne en Crète - et non en Grande-Grèce - daté du I $\mathrm{I}^{\mathrm{e}}$ ou du II ${ }^{\mathrm{e}}$ siècle de notre ère - il est donc postérieur d'au moins six siècles à Pythagoras. Une note à la fin du chapitre, il est vrai, suggère que le groupe de marbre « pourrait (...) être la copie » du groupe de bronze de Pythagoras. Dès lors, une hypothèse formulée en note devient une certitude dans le corps du texte.

À moins que Virgile n'ait écrit l'Énéide en distiques élégiaques, on voit mal comment les vers Invida si Tauri vidisset Juno natatus / Iustius Aeolias isset ad usque domos pourraient être tirés de ce poème, comme l'écrit Mme Wattel. Ces vers, inscrits sur la mosaïque de Lullingstone, sont simplement une allusion au début de l'Énéide (I, 50-53) et veulent dire que si la jalouse Junon avait vu nager le taureau, elle aurait eu de bonnes raisons d'aller à la demeure d'Éole, des raisons meilleures encore que celles qui la faisaient poursuivre les Troyens.

Et l'on pourrait citer d'autres exemples de ce genre. En définitive, pour interpréter les représentations figurées, qui font allusion à des traditions religieuses et littéraires, il est indispensable de lire et d'étudier correctement les textes.

Catherine LECOMTE

(Université de Liège)

Stella Georgoudr, Jean-Pierre Vernant (éds), Mythes grecs au figuré, de l'antiquité au baroque, Paris, Gallimard, 1996. 1 vol. $16,5 \times 21 \mathrm{~cm}, 234$ p., 58 ill. (Coll. Le temps des images). ISBN : 2-07-73910-4.

Depuis quelques années déjà, le mythe grec fait l'objet de discussions passionnées et passionnantes, dont Jean-Pierre VERNANT fait état dans un chapitre introductif sur Les frontières du mythe. Mais ce sont plus particulièrement les rapports entre les récits mythiques et leur transposition figurative, d'une part, et le cheminement de certains mythes qui se détachent de leur origine pour se donner de « nouveaux habits », d'autre part, qu'illustrent ces quelques "échantillons » issus d'un colloque tenu à Delphes en 1993 sur La mythologie grecque et l'art baroque.

Puisque, décidément, la Grèce est au centre dès qu'on parle de « mythe », c'est en Grèce que commence ce parcours tout en questions; car dès le $\mathrm{v}^{\mathrm{e}}$ siècle av. J.-C., on interroge les mythes : "façons de dire traditionnelles et non fiables » pour Platon, fabulations invérifiables pour Thucydide, mais aussi histoires fondatrices qu'il convient d'harmoniser et d'articuler entre elles pour les logographes, les mythes deviennent peu à peu, - surtout avec l'époque impériale et la mise sous tutelle d'une Grèce en quête de sa nouvelle identité, - une mythologie, un savoir spécifique, un champ d'étude particulier, délié de la littérature, séparé de l'histoire et à l'écart des enjeux idéologiques traditionnels. Ils sont alors prêts pour les transformations et les resémantisations des siècles suivants (J.-P. VernANT). Avant d'envisager, avec Danaé (Fr. LisSARAGUE) et Andromède (Fr. Frontisi-DucrouX), ce que sont certaines de ces transformations, la Grèce nous retient encore avec ce curieux «panthéon condensé » que forment les "Douze dieux » (St. GeORGOUdi). Sur le terrain des pratiques, des narrations mythiques et des représentations figurées, les idées reçues à leur sujet depuis l'article d'O. WEINREICH dans le Lexicon de ROSCHER sont systématiquement mises en cause, avec une grande force de conviction : il est tout aussi vain d'en chercher l'origine en Ionie que d'en établir un prétendu "canon », en fait introuvable. 
Et le mythe à Rome ? Encore une question difficile, à laquelle M. BEARD entreprend d'apporter quelques éléments de réponse sur le ton de la provocation, consciente et assumée, autour de la figure monstrueuse de l'Hercule Farnèse qui ornait les thermes de Caracalla. Si le mythe est bien, comme elle l'entend, une «stratégie culturelle » qui permet de discuter la vérité, alors cet Hercule aux bains appartient au «mythe de la vérité des bains », activité typiquement romaine, et devait interpeller le baigneur sur sa virilité, sur le ridicule aussi, tout autant que sur la grécité sans cesse « au cœur de toute chose romaine ». Le pari est intéressant, mais pas entièrement convaincant. Sans doute l'hellénocentrisme est-il encore trop prégnant!

Les deux dernières contributions du volume étudient respectivement la mythologie à l'âge " baroque » et les nouveaux territoires du mythe au XVIII ${ }^{\mathrm{e}}$ siècle. Il s'agit tout d'abord de comprendre comment une religion toute-puissante et exclusive comme la religion catholique a pu accepter une mythologie qui lui est étrangère. Dans le conflit d'intérêt posé par la " gestion » de l'héritage antique, la Contre-Réforme a tranché avec prudence et favorisé l'« humanisme dévôt ». Les scrupules éventuels ont été calmés par « la mise en perspective historique de la mythologie comme stade primitif de l'humanité » et par les efforts consentis pour en faire un langage abstrait. Elle est peu à peu devenue une agréable convention dépourvue de tout danger (J. THuiluER). Mais les artistes vont progressivement se libérer des traditions héritées de la Renaissance pour favoriser les apports de l'archéologie, conjugués à l'inspiration littéraire, dans la représentation des thèmes antiques. Le souci d'une connaissance raisonnée destinée à restaurer «scientifiquement » les sculptures va les guider. Pier $\mathrm{L}$. Ghezzi, le comte de Caylus et Winckelmann constituent autant d'étapes de ce nouveau regard (J. RASPI-SERRA).

Un très beau volume, aux larges perspectives et aux illustrations remarquables.

Vinciane PIRENNE-DELFORGE

(Université de Liège)

Jean ADHÉmar, Influences antiques dans l'art du Moyen âge frangais. Préface de Léon Pressouyre, Édition du Comité des Travaux Historiques et Scientifiques, 1996, 463 p., 127 fig. (Format 21).

Cet ouvrage est en fait la réédition de la thèse de doctorat de l'A., mort en 1987, archiviste-paléographe, élève de Focillon et disciple d'Ady Warburg, Influences antiques dans l'art du Moyen âge français. Recherches sur les sources et les thèmes d'inspiration, London, The Warburg Institute, 1939. Cette thèse devait clore de vieux débats en démontrant principalement que l'influence antique n'avait cessé de s'exercer pendant les « siècles obscurs » du Moyen âge.

L'économie générale de l'ouvrage repose sur ce présupposé : « une "Renaissance" au sens d'imitation volontaire et consciente de l'antique n'est possible et viable qu'à deux conditions : l'amour des lettres classiques connues d'après les originaux et un vif sentiment de la beauté des témoins matériels ». L'A. retrace donc d'abord l'histoire des études classiques et de l'humanisme au Moyen âge qui connaissent une floraison brillante sous Charlemagne ainsi qu'aux $\mathrm{XI}^{\mathrm{e}}$ et $\mathrm{XII}^{\mathrm{e}}$ siècles. Cet humanisme est nourri tantôt par la lecture assidue de manuscrits d'auteurs classiques préservés dans les bibliothèques monastiques, tantôt par celle d'adaptations très éloignées de véritables traductions. L'A. ne s'attarde ni sur le préhumanisme du $\mathrm{XV}^{\mathrm{e}}$ siècle ni sur les signes 